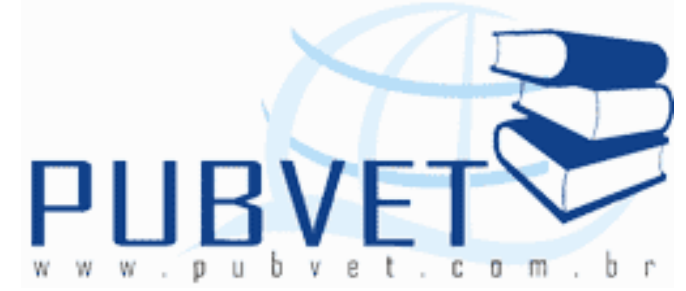

PUBVET, Publicações em Medicina Veterinária e Zootecnia.

Disponível em: <https://doi.org/10.31533/pubvet.v02n11a449>.

\title{
Avaliação de diferentes misturas de sementes como ração para pássaros de interesse comercial da fauna exótica
}

Paulo César Brustolini ${ }^{1}$, Francisco Carlos de Oliveira Silva ${ }^{2}$, Ana Paula Liboreiro Brustolini ${ }^{3}$, Eduarto Teixeira Lanna ${ }^{4}$, Cinthia Maria Carlos Pereira ${ }^{5}$

${ }^{1}$ Professor Departamento Zootecnia - UFV - Viçosa, MG

2Pesquisador EPAMIG / CTZM- Viçosa, MG

${ }^{3}$ Estudante graduação Zootecnia da UFV

${ }^{4}$ Professor Departamento Zootecnia - UFV - Viçosa,MG

${ }^{5}$ Estudante graduação Zootecnia da UFV

\section{RESUMO}

Foram utilizados 12 trinca-ferros machos adultos, com o objetivo de avaliar 0 efeito de diferentes misturas dietéticas sobre o desempenho dos pássaros. Foi distribuída em delineamento experimental inteiramente casualizado com três tratamentos e quatro repetições por tratamento sendo considerada uma ave por unidade experimental. As variáveis de desempenho foram determinadas mediante observações diárias e pesagens das aves e das respectivas sobras de rações durante todo período experimental, que se encerrou após 45 dias de experimentação. As análises estatísticas das variáveis de desempenho foram analisadas pelo sistema de teste de média Duncan ao nível de $5 \%$ de 
probabilidade. $O$ peso final dos trinca-ferros não foi afetado $(P>0,05)$ pelos tratamentos. Entretanto, a maior variação de peso foi observada para os pássaros consumindo ração comercial, que tiveram um ganho 2,9\% superior quando comparados aos pássaros que consumiram a ração triturada. $O$ consumo total de ração também não foi influenciado $(P>0,10)$ pelos tratamentos. Não foi observado efeito $(P>0,10)$ no consumo médio diário de ração (CMR) e. no consumo médio de água dos trinca-ferros pelos tratamentos. A atividade de canto foi influenciada pelos tratamentos, o melhor desempenho de canto foi apresentado pelos pássaros que consumiram a ração peletizada enquanto que o pior desempenho ficou com os pássaros que receberam a ração comercial. Os tratamentos, não influenciaram $(P>0,05) 0$ número médio de evacuações diárias. Não houve diferenças $(P>0,05)$ quanto ao empenamento indicando que as aves estavam em boas condições de saúde. Os valores de Energia Bruta das diferentes rações utilizadas no experimento, foram de 4.279,80 kcal/kg (Ração Comercial); 4.551,30 kcal/kg (Ração Triturada) e 4.010,80 kcal/kg (Ração Peletizada). Os valores de Energia Metabolizável foram, respectivamente, de 2.334,66 $\mathrm{kcal} / \mathrm{kg}$ (Ração Comercial), de $2.746,81 \mathrm{kcal} / \mathrm{kg}$ (Ração Triturada) e $2.807,81 \mathrm{kcal} / \mathrm{kg}$ (Ração Peletizada). Concluiu-se que o consumo médio diário de alimentos foi de 8,94 g/dia, o de água foi de 28,35 I/dia; A ração comercial utilizada (T1), provocou variação positiva no peso dos trinca-ferros $(+1,25 \mathrm{~g})$ enquanto a ração experimental triturada e adicionada de uma mistura de sementes (T2), provocou variação negativa no peso dos pássaros $(-1,75 \mathrm{~g})$.

\section{Assessment of different mixtures of seeds to feed the birds of interest commercial exotic fauna}

\section{ABSTRACT}

We used 12 adult male Trinca-Ferro, to evaluate the effect of different dietary mixtures on the performance of the birds. It was distributed in a completely 
randomized design with three treatments and four replicates per treatment is considered experimental unit for a bird. The variables of performance were determined by daily observations and weighing the birds and their surplus of rations throughout the trial period, which ended after 45 days of testing. Statistical analyses of performance variables were analyzed by the system test average Duncan at $5 \%$ probability.The final weight of the Trinca- Ferro was not affected $(P>0.05)$ by treatments. Meanwhile, the biggest change in weight was observed to feed the birds consuming business, which had a gain $2.9 \%$ higher when compared to birds that consumed the feed crushed. The total consumption of feed was not influenced $(P>0.10)$ by treatments. There was no effect $(P>0.10)$ in average daily consumption of feed $(C M R)$ e. the average consumption of water from the Trinca- Ferro by treatments. The activity of singing was influenced by treatments, the best performance of call was made by birds that consumed the feed pelleted while the worst performance was with the birds that received the feed business. The treatments, did not influence $(P>0.05)$ the average number of daily evacuations. There were no differences $(P>0.05)$ on the empenamento indicating that the birds were in good health. The values of Energy Gross of different diets used in the experiment, were 4.279,80 kcal / kg (Commercial Feed); 4.551,30 kcal / kg (Feed Triturada) and 4.010,80 kcal / kg (Feed Peletizada). The values of Energy Metabolizável were respectively $2.334,66 \mathrm{kcal} / \mathrm{kg}$ (Commercial Feed), $2.746,81 \mathrm{kcal} / \mathrm{kg}$ (Feed Triturada) and 2.807,81 kcal / kg (Feed Peletizada). It was concluded that the average daily consumption of food was $8.94 \mathrm{~g} /$ day, the water was 28.35 litres per day, the commercial feed used (T1), caused positive change in weight of the crack-irons $(+1.25 \mathrm{~g})$ while the experimental diet crushed and added to a mixture of seeds (T2), caused no change in weight of the birds. 


\section{INTRODUÇÃO}

O Trinca- Ferro é um pássaro que necessita de uma dieta bem balanceada e muito nutritiva, devido ao seu porte e características de atividade, assim como ocorre com o sabiá e o pássaro preto.

Por ser um pássaro onívoro, existe uma grande variação de alimentos na formulação de sua dieta: grande variedade de sementes (alpiste, painços, girassol, arroz, aveia, cártamo, cânhamo, lentilha, sorgo, etc.), entrando ainda as rações peletizadas, extruzadas, frutas, legumes e insetos (larvas, grilos). Essas características acabam complicando para quem quer criar em larga escala, pois dificulta o manejo, higiene e podendo levar as aves a ter diarréias, intoxicações diversas entre outros problemas.

Segundo Wenceslau (2003), uma alimentação errada pode intervir de modo significativo na criação, afetando a saúde dos animais e gerando problemas de infertilidade.

Outro problema verificado, é que a ave pode adquirir preferência por certos alimentos, como sementes maiores e mais oleosas, causando desequilíbrio em sua dieta, levando à obesidade e subnutrição (Reis, 2003).

De acordo com Reis (2003), o ideal seria que o pássaro recebesse uma dieta única, onde pudesse ter à sua disposição todos os nutrientes de que necessita (proteínas, açúcares, gorduras, carboidratos, vitaminas e minerais). Isso, só será possível com a utilização de ração balanceada e oferecida na forma peletizada e/ou extruzada, no sentido de obtermos melhores resultados.

Mesmo para os pássaros comedores de sementes, existe a necessidade de uma suplementação, pois alimentá-los só com sementes não é muito apropriado, ainda que diferentes tipos de sementes sejam fornecidos elas não são capazes de suprir todas as necessidades nutricionais (Foster \& Smith, 2004).

Pássaros criados em cativeiro precisam de dietas equilibradas e palatáveis. Estudos sobre pássaros em cativeiro alimentados principalmente com 
sementes de plantas cultivadas sugerem que estes não demonstram a mesma sabedoria nutricional daqueles de vida livre (Ulrey et al, 1994).

A realidade atual é que devido ao aumento do interesse pelos pássaros como animal de estimação nos últimos anos (fácil manutenção em apartamentos, decorativas, menos dispendiosas), fez crescer a demanda por produtos de qualidade. Além desses fatores, a profissionalização mundial dessa atividade é cada vez maior.

Assim, as alternativas alimentares com algum embasamento científico, que contemplem as reais necessidades dietéticas dos pássaros só serão possíveis à medida que pesquisas de cunho científico forem realizadas a fim de esclarecer todos os problemas pertinentes ao assunto, já que a maioria das informações existentes hoje em dia, não têm origem nas pesquisas, e a maioria delas é baseada em "achismos", meras formulas caseiras.

Neste contexto, o presente trabalho teve por objetivos: 1) Testar três diferentes rações para trinca-ferro, sendo uma comercial e duas formuladas para a pesquisa, com a inclusão de um premix mineral e vitamínico, no desempenho dos pássaros e, 2) Fazer um estudo comparativo da digestibilidade dessas rações.

\section{MATERIAL E MÉTODOS}

Os experimentos foram conduzidos nas dependências do Departamento de Zootecnia do Centro de Ciências Agrárias da Universidade Federal de Viçosa, Viçosa, MG.

Foram utilizados doze pássaros (Trinca-Ferro) machos adultos, alojados em gaiolas individuais. Os pássaros foram distribuídos em delineamento experimental inteiramente casualizado com três tratamentos e quatro repetições por tratamento, sendo cada ave considerada uma unidade experimental. 
Os pássaros foram adquiridos de criadores idôneos e devidamente credenciados pelo IBAMA. Após a aquisição todos os pássaros passaram por um exame clinico e um rigoroso controle sanitário.

Os tratamentos ficaram assim distribuídos:

T1- Ração Comercial: recomendada para sabiás, pássaro preto e trincaferro.

Composição básica: Milho moído (53,3\%), farelo de soja, farelo de trigo, farinha de carne e ossos, calcário calcítico, sal comum, premix mineral e vitamínico e adicionada de essência de banana. Níveis de garantia: Cálcio (máximo) 1,0\%; Fósforo (mínimo) 0,3\%; Proteína Bruta 12\%; Umidade (máxima) $13 \%$.

T2- Ração Triturada: indicada para sabiás, pássaro preto, trinca-ferro e outros. Composição básica: Milho integral triturado, frutas cristalizadas, ração granulada, semente de girassol, amendoim farelo, arroz em casca, farinha de carne e ossos, premix mineral e vitamínico, propionato de Cálcio. Níveis de garantia: Proteína bruta $15 \%$; Cálcio (máximo) 1,0\%; Umidade (máxima) 13\%; Fósforo (mínimo) 0,30\%.

T3- Ração Peletizada: indicada para sabiá, pássaro preto, trinca-ferro e outros. Composição básica: Sorgo grão triturado, glúten de milho, fosfato bicálcico, calcário calcitico, sal comum, L.Lisina, premix mineral e vitamínico. Níveis de garantia: Proteína bruta 15\%; Cálcio (máximo) 1,0\%; Umidade (máxima) 13\%; Fósforo (mínimo) 0,30\%.

As rações e água foram fornecidas à vontade, sendo as sobras coletadas duas vezes ao dia para cálculo do consumo. Foram avaliados os seguintes parâmetros:

- Consumo de ração;

- Consumo de proteína;

- Consumo de energia; 
- Empenamento e qualidade das penas: 1 = pássaro com o empenamento em estado precário; 2 = pássaro com o empenamento ruim; 3 = pássaro com o empenamento razoável; 4 = pássaro com bom empenamento e, 5 = pássaro com empenamento excelente;

- Canto e atividade física;

- Número de evacuações diárias e consistência da excreta;

- Variação de peso das aves.

As temperaturas média diárias, máxima e mínima, no interior do galpão foram registradas utilizando-se um termômetro de máxima e mínima colocado à mesma altura das aves.

As variáveis de desempenho foram determinadas mediante observações diárias e pesagens das aves e das respectivas sobras de ração durante o período experimental. Foram determinadas também as análises da composição química e bromatológica das rações utilizadas.

De cada tipo de ração foram retiradas três amostras consideradas como repetição, que foram submetidas á análise proximal segundo metodologia descrita por Silva (1990).

As análises bromatológicas das rações foram realizadas nas dependências do laboratório de Nutrição Animal do DZO/UFV, segundo a metodologia descrita por Silva (1990).

As análises estatísticas das variáveis de desempenho foram analisadas pelo sistema de teste de média Duncan ao nível de $5 \%$ de probabilidade.

\section{RESULTADOS E DISCUSSÃO}

As temperaturas máxima e mínima em que o experimento foi realizado foram $25,52{ }^{\circ} \mathrm{C}$ e $22,0^{\circ} \mathrm{C}$, respectivamente, com uma umidade relativa média de $74,7 \%$.

Os resultados obtidos de variação de peso (VP); consumo total de ração (CTR); consumo médio diário de ração (CMR); número de evacuações diárias 
Brustolini, P.C., Silva, F.C.O., Brustolini, P.L. et al. Avaliação de diferentes misturas de sementes como ração para pássaros de interesse comercial da fauna exótica. PUBVET, Londrina, V. 2, N. 46, Art\#449, Nov3, 2008.

(FEZES); escore corporal (EP); atividade de canto (CANTO) e empenamento (PENA) para trinca-ferros, são apresentados na Tabela-1.

$O$ peso final dos trinca-ferros utilizados no presente experimento, não foi afetado $(P>0,05)$ pelos tratamentos e estão de acordo com os citados por Nuno, (2002) e Scharra (1986), que reportam um peso médio para trinca-ferro de 45,0 gramas, embora os pássaros que receberam a ração triturada tenham experimentado uma variação negativa de peso $(-1,75 \mathrm{~g})$ ao final do experimento.

Tabela 1 - Peso inicial, peso final, variação de peso, consumo total de ração, consumo diário de ração, consumo de água, número de evacuações diárias, empenamento e atividade de canto de trinca-ferros consumindo diferentes dietas experimentais.

\begin{tabular}{|c|c|c|c|c|}
\hline \multirow[b]{2}{*}{ Parâmetros } & \multicolumn{3}{|c|}{ Tratamentos } & \multirow{2}{*}{$\begin{array}{l}\mathrm{CV} \\
(\%)\end{array}$} \\
\hline & $\begin{array}{l}\text { Ração } \\
\text { comercial }\end{array}$ & $\begin{array}{l}\text { Ração } \\
\text { Triturada }\end{array}$ & $\begin{array}{l}\text { Ração } \\
\text { Peletizada }\end{array}$ & \\
\hline Peso inicial $(\mathrm{g})$ & 46,26 & 45,25 & 43,25 & 4,40 \\
\hline Peso final $(\mathrm{g})$ & 47,50 & 40,25 & 44,25 & 11,60 \\
\hline Variação de peso $(\mathrm{g})$ & 1,25 & $-1,75$ & 0,75 & - \\
\hline $\begin{array}{l}\text { Consumo total de ração } \\
\text { (g) }\end{array}$ & 349,50 & 298,75 & 341,50 & 15,42 \\
\hline $\begin{array}{l}\text { Consumo diário de ração } \\
\text { (g) }\end{array}$ & 9,45 & 8,07 & 9,30 & 15,42 \\
\hline Consumo de água $(\mathrm{ml})$ & 29,70 & 25,95 & 29,40 & 24,16 \\
\hline $\begin{array}{l}\text { Atividade de canto } \\
\text { (escore) }\end{array}$ & $1,00 a$ & $1,75 b$ & $2,75 a$ & 39,63 \\
\hline $\begin{array}{l}\text { Número médio de } \\
\text { evacuações }\end{array}$ & 26,72 & 32,00 & 31,50 & 15,43 \\
\hline Empenamento (escore) & 4,25 & 4,75 & 5,00 & 10,74 \\
\hline
\end{tabular}

A maior variação de peso foi observada para os pássaros consumindo ração comercial, que tiveram um ganho 2,9\% superior quando comparados aos pássaros consumindo ração triturada. Esse fato, provavelmente aconteceu em função do menor consumo de ração, $(8,07 \mathrm{~g} / \mathrm{dia})$ e maior quantidade de 
Brustolini, P.C., Silva, F.C.O., Brustolini, P.L. et al. Avaliação de diferentes misturas de sementes como ração para pássaros de interesse comercial da fauna exótica. PUBVET, Londrina, V. 2, N. 46, Art\#449, Nov3, 2008.

excretas (32 evacuações/dia) observados com o consumo da ração triturada. 0 aumento de peso observado com o consumo da ração comercial $(1,24 \mathrm{~g})$ embora não significativo, sugere que por períodos prolongados pode levar os pássaros à obesidade, o que é altamente indesejável.

$O$ consumo total de ração também não foi influenciado $(P>0,10)$ pelos tratamentos. Entretanto, verificou-se que numericamente o maior consumo de ração pelos pássaros foi verificado utilizando a ração comercial e o pior consumo com a triturada. Do mesmo modo, Wolf e Kamphues (2003) testando diferentes rações comerciais para canários belga e agapornis, verificaram diferenças entre o consumo das mesmas e, concluíram em seus estudos, que as rações comerciais que existem no mercado para esses pássaros nem sempre atendem plenamente as exigências dos mesmos, isso indica que há necessidade de desenvolvimento de mais estudos para que possamos calcular dietas mais precisas. (REPETIU)

O consumo médio diário de alimentos (CMR) não foi influenciado $(P>0,10)$ pelos tratamentos. Contudo, numericamente, constatou-se que o maior consumo foi verificado na utilização da ração comercial $(9,45 \mathrm{~g})$, enquanto que o menor consumo foi verificado com a ração triturada $(8,07 \mathrm{~g})$, ficando a peletizada com um consumo médio de ração/dia de 9,30 g. Estes resultados diferem dos encontrados por Wolf e Kamphues (2003), verificaram diferenças significativas entre os consumos das mesmas, e concluíram em seus estudos, que na maioria das vezes, as rações comerciais existentes no mercado não atendem plenamente as exigências nutricionais dos mesmos, indicando a necessidade de mais estudos para que se possam calcular dietas mais precisas, já que tanto a obesidade quanto desnutrição são prejudiciais (March, 2002). Além disso, em nenhum animal a digestão é perfeita, existem perdas e ineficiências ao longo desse processo. Para a maioria dos alimentos a digestão das aves apresentam uma eficiência de $65 \%$ podendo chegar com a utilização dos produtos da soja aos 75\% (McDonald, 1986). Neste estudo, o menor consumo de ração verificado na utilização da ração triturada, talvez se deva ao nível energético da dieta, que foi maior que dos demais tratamentos, já 
Brustolini, P.C., Silva, F.C.O., Brustolini, P.L. et al. Avaliação de diferentes misturas de sementes como ração para pássaros de interesse comercial da fauna exótica. PUBVET, Londrina, V. 2, N. 46, Art\#449, Nov3, 2008.

que os animais tendem a consumir para satisfazer suas necessidades energéticas.

Não foi observado efeito dos tratamentos sobre o consumo de água dos trinca-ferros, que foi em média de 28,35 ml/dia. Esses resultados estão de acordo com os citados por Scharra (1986) que reporta um consumo médio de água para trinca-ferro da ordem de $30 \mathrm{ml} / \mathrm{dia}$.

A atividade de canto foi influenciada pelos tratamentos, o melhor desempenho de canto foi apresentado pelos pássaros que consumiram a ração peletizada, enquanto que o pior desempenho ficou com os pássaros que consumiram a ração comercial. Estes resultados podem ou não ter sofrido influência das dietas, já que canto é um fator genético.

Os tratamentos, não influenciaram $(P>0,05)$ o número médio de evacuações diárias (FEZES), embora os trinca-ferros que consumiram a ração triturada, onde foi observado um menor consumo de ração, tenham excretado um volume de fezes $1,4 \%$ maior em relação aos outros tratamentos. A qualidade da excreta (aspecto, consistência, etc), também não apresentou nenhum tipo de variação, ficando perfeitamente normal nos três tratamentos, indicando que os tratamentos não provocaram nenhum tipo de distúrbio intestinal nos animais experimentais. Apesar da dificuldade de se encontrar dados na literatura a esse respeito, os resultados do presente estudo podem ser comparados aos citados por Scharra, (1986) que cita um número médio de evacuações diárias para pássaros de 25 a 30 vezes/dia em condições normais de alimentação e saúde.

Não houve diferenças significativas $(P>0,05)$ quanto ao empenamento (PENA) indicando que as aves estavam em boas condições de saúde, já que a plumagem funciona como um agente indicador de saúde. Segundo Wolf e Kamphues (2003), problemas de empenamento são comuns em rações deficientes em aminoácidos sulfurosos.

Os resultados obtidos de energia bruta (EB), proteína bruta (PB), energia metabolizável (EM) e coeficiente de digestibilidade das rações utilizadas são apresentados na Tabela-2. 
Brustolini, P.C., Silva, F.C.O., Brustolini, P.L. et al. Avaliação de diferentes misturas de sementes como ração para pássaros de interesse comercial da fauna exótica. PUBVET, Londrina, V. 2, N. 46, Art\#449, Nov3, 2008.

Tabela 2 - Energia Bruta (EB), Energia Metabolizável (EM), Proteína Bruta e Coeficiente de Metabolizabilidade (CMET) das dietas determinado com TrincaFerros.

\begin{tabular}{lccc}
\hline \multicolumn{1}{c}{ DIETAS } & EB & EM & PB \\
& $(\mathrm{kcal} / \mathrm{kg})$ & $(\mathrm{kcal} / \mathrm{kg})$ & $(\%)$ \\
\hline Ração Comercial & $4.279,80$ & $2.334,66$ & 14,08 \\
Ração Triturada & $4.551,30$ & $2.746,81$ & 16,72 \\
Ração Peletizada & $4.010,80$ & 2.807 .81 & 13,63 \\
\hline
\end{tabular}

Os valores de Energia Bruta encontrados nas diferentes rações utilizadas no experimento, foram de 4.279,80 kcal/kg (Ração Comercial); 4.551,30 $\mathrm{kcal} / \mathrm{kg}$ (Ração Triturada) e 4.010,80 kcal/kg (Ração Peletizada), valores aparentemente elevados.

O valor determinado de Energia Metabolizável de 2.334,66 kcal $/ \mathrm{kg}$ que foi observado com o consumo a ração comercial, está abaixo daqueles recomendados pelo INRA (1984), que recomenda $2.900 \mathrm{kcal} / \mathrm{kg}$ de EM para faisões e perdizes e por Cotta (2003), que cita uma variação entre 2.500 a $3.000 \mathrm{kcal}$ de EM/kg de ração para faisão.

Devido às suas características de comportamento, os pássaros encontramse mais próximos aos faisões e perdizes quanto às suas exigências alimentares, e estes exigem uma taxa energética alimentar compreendida entre 2.500 e $3.000 \mathrm{kcal}$ de EM/kg, segundo Oliveira, (1999).

Os valores encontrados de EM para as rações triturada e peletizada foram respectivamente de $2.746,81 \mathrm{kcal} / \mathrm{kg}$ e $2.807,81 \mathrm{kcal} / \mathrm{kg}$, estão de acordo com a literatura no que diz respeito a codornas e faisões (INRA, 1984; NRC, 1994 e Cotta, 2003).

Para a maioria dos alimentos a digestão das aves apresenta uma eficiência de $65 \%$, chegando, no caso dos produtos da soja, aos $75 \%$ (Macdonald, 1986). Somado a esse relato e com base nos resultados, pode-se inferir o 
Brustolini, P.C., Silva, F.C.O., Brustolini, P.L. et al. Avaliação de diferentes misturas de sementes como ração para pássaros de interesse comercial da fauna exótica. PUBVET, Londrina, V. 2, N. 46, Art\#449, Nov3, 2008.

processamento pode ter melhorado a eficiência digestiva da com a ração peletizada (T3).

Normalmente, rações contendo grãos integrais (Comercial e Triturada), sofrem perda de digestibilidade devido a grande quantidade de cascas não digeríveis e exigem uma complementação da alimentação, garantindo assim a suplementação diária para um ótimo desempenho e excelentes condições gerais de manutenção dos pássaros criados em cativeiro. Essa suplementação é de fundamental importância, principalmente no período de reprodução.

\section{CONCLUSÕES}

Nas condições em que o experimento foi realizado, pode-se concluir que o consumo médio diário de alimentos foi de $8,94 \mathrm{~g} /$ dia e o consumo médio diário de água foi de $28,35 \mathrm{ml} /$ dia. Entretanto, o consumo da ração comercial proporcionou variação positiva no peso dos trinca-ferros $(1,25 \mathrm{~g})$ enquanto a ração triturada e adicionada de uma mistura de sementes, resultou variação negativa no peso dos pássaros $(1,75 \mathrm{~g})$, sendo os melhores resultados obtidos com a ração peletizada.

\section{AGRADECIMENTO}

Os autores agradecem ao Laboratório Simões pela oportunidade de desenvolver a pesquisa.

\section{REFERÊNCIAS BIBLIOGRÁFICAS}

ANDRigueto, J. M. et al. Nutrição Animal. 3 ed. Livraria Nobel, São Paulo, 1983.

BASIC BIRD NUTRITION - Jennifer Prince D. V. M. Drs. Foster Smith, Veterinary Service Department - Winscosin Veterinary Medical Association.,2004

BELTON, W. Aves Silvestres do Rio Grande do Sul, 2 ed. Porto Alegre, Fundação Zoobotânica do Rio Grande do Sul, 1986. 
Brustolini, P.C., Silva, F.C.O., Brustolini, P.L. et al. Avaliação de diferentes misturas de sementes como ração para pássaros de interesse comercial da fauna exótica. PUBVET, Londrina, V. 2, N. 46, Art\#449, Nov3, 2008.

BRAGA, J.M. Avaliação da fertilidade do solo. Ensaios de campo. Viçosa-MG: UFV, Imprensa Universitária, 1983. 101p.

COTTA, T. Alimentação de aves. Viçosa, MG: Aprenda Fácil, 2003. 238p.

GOMES, A. C. Alimentação: Consciência e Orientação. Revista Passarinheiros e Cia. n. 15, p. 31,2002.

HOSKEN, M. F. e SILVEIRA, C. A. Criação de Curiós e Bicudos. 1 ed. Livraria Aprenda Fácil, 200p. Viçosa-MG, 2000

HOSKEN, M. F. e SILVEIRA, C. A. Criação de Canário da Terra. 19 ed. Livraria Aprenda Fácil, 200p. Viçosa-MG, 2000.

INRA. L'alimentation desanimaux monogastriques: porc,lapin,volailles. Ed. INRA, Paris, 1984, $283 p$.

McDONALD, et al. Animal Nutrition, McGraw-Hill. 1986

MARCH. M. Artigo Sobre Alimentação de Pássaros Extraído da Internet. setembro, 2002.

MARQUES, H. L. Aumento da Produção. Suinocultura Industrial, no 01, Ed. 166; 2003.

MIGUEL, S. R. Alimentação: Consciência e Orientação. Revista Passarinheiros e Cia. n.15, p.31,2002.

MUNNO, W. T. Dicas para Salvar seus Canários. Rev. Pássaros ,n.3, 2001.

NRC, National Ressearch Council. Nutritional requirements of council. . Washington, DC: National Aacademic Science, 1994..

OLIVEIRA, P. M. Alimentação dos Animais Monogástricos: Suínos, Coelhos e Aves. São Paulo: Roca, 1999. 245p.

ROSTAGNO, H.S. et al. Composição de alimentos e exigências nutricionais de aves e suínos (Tabelas Brasileiras). Viçosa-MG: UFV, 2000.

REIS. D. C. Criação de Trinca-Ferro (Dicas Interessantes). Confederação Brasileira dos Criadores de Pássaros Nativos. COBRAP, 2005.

SChARRA, F. M. D. Doença dos Pássaros e outras Aves. Rev. Cátedra, Rio de janeiro, 1986.

TORRES, A. P. Alimentos e Nutrição das Aves Domésticas. 9ed Livraria Nobel, $\mathrm{SP}, 1989$

TOSTES, A.P. Uma Visita ao Criatório de Aloísio Pacini Tostes. Atualidades ornitológicas, Ivaiporã, n.62.1984.

TOSTES, A. P. Criação de Curiós e Bicudos. Editora e Gráfica Scala, Ribeirão Preto, SP, 1997.

UNIVERSIDADE FEDERAL DE VIÇOSA. Central de Processamento de Dados UFV/CPD. SAEG Sistema para análise estatística e genética. Viçosa, MG. 52p. 1987.

WENCESLAW. C. G. C. Alimentação de Pássaros Granívoros. (considerações sobre o manejo alimentar em Passeriformes granívoros). Confederação Brasileira dos Criadores de Pássaros Nativos. COBRAP, 2005.

WOLF, P. e KAMPHUES, J. Hand rearing of pet birds-feeds, techiniques and recommendations. J. Anim. Physiol. Nutr. 87, 122-128. 2003. 